\title{
Distance to family members and relocations of older adults
}

\author{
Albertine M. L. van Diepen • Clara H. Mulder
}

Received: 20 December 2007 / Accepted: 13 October 2008 / Published online: 12 November 2008

(C) The Author(s) 2008. This article is published with open access at Springerlink.com

\begin{abstract}
For older people, proximity to family members may well be highly valuable. In this paper, we investigate to what extent the relocation behaviour of older people is associated with the distance to their children and siblings. For the analysis, we have used data from the Netherlands Kinship Panel Study. This dataset includes detailed geographical information about places of residence. We employ descriptive analyses and multinomial logistic regression of moving closer to family members and moving away from them. We find that, with increasing distance to children, older people are more inclined to move closer to their children and slightly less inclined to move away from them. The findings for moving closer to and away from siblings are similar, but less pronounced. We also find that older people with grandchildren are more likely to move closer to their children than those without grandchildren. No influence of health problems on relocations of older adults is found.
\end{abstract}

Keywords Older adults $\cdot$ Relocation behaviour $\cdot$ Distance $\cdot$ Family $\cdot$ Children $\cdot$ Siblings

\section{Introduction}

Family is important in the contact- and care-provision networks of the elderly. Even in our western society, which is often considered to be individualistic, intergenerational solidarity and dependence are still strong (Bengtson 2001; Komter and Vollebergh 2002; Rossi and Rossi 1990). Older adults are both receivers (Silverstein 1995) and providers (Morgan et al. 1991; Van Tilburg et al. 1995; Remery et al. 2000) of instrumental and emotional support from and for family members.

The frequency of contact between family members is influenced by the geographic distance between their places of residence: the greater the distance to family members, the less

\footnotetext{
A. M. L. van Diepen $(\bowtie) \cdot$ C. H. Mulder

Department of Geography, Planning and International Development Studies, AMIDSt, University of Amsterdam, Nieuwe Prinsengracht 130, 1018 VZ Amsterdam, The Netherlands e-mail: a.m.l.vandiepen@uva.nl

C. H. Mulder

e-mail: c.h.mulder@uva.nl
} 
frequent is the contact, particularly at short and medium distances (Lee et al. 1990; Bengtson and Roberts 1991; Grundy and Shelton 2001; Lawton et al. 1994; Smith 1998; Glaser and Tomassini 2000; Hank 2007). The provision of care and support for family members also takes place less often when the distance between the places of residence is greater (Daatland and Lowenstein 2005; De Jong Gierveld and Fokkema 1998; Knijn and Liefbroer 2006; Joseph and Hallman 1998; Tomassini et al. 2003). Considering the importance to family members of a small geographic distance, it could be expected to influence the relocation behaviour of older adults: they might well be inclined to relocate in the direction of their children and/or siblings, or similarly be reluctant to relocate away from them.

Previous research on the direction of migration of older adults with respect to family members is scarce and focuses mainly on migration towards adult children (Law and Warnes 1982; Litwak and Longino 1987; Rogerson et al. 1997; Speare and McNally 1992; Silverstein 1995). The aim of this article is the enhancement of our understanding of the extent to which the relocation behaviour of older adults in the Netherlands is influenced by the distance not only to children, but also to siblings. We have used data from the first wave of the Netherlands Kinship Panel Study and multinomial logistic regression analysis. As this dataset includes people not older than 79 years of age, our study deals with the 'young elderly'. In this study, by relocation behaviour we mean whether or not there has been relocation in combination with its direction: does the relocation lead to a reduction of the distance to the family member living closest or, conversely, to an increase? Together with the change in the shortest distance to other family members, other relevant characteristics of the older adults and their residential situation that could influence the distance to family members and the relocation behaviour are included in the analyses.

\section{Hypotheses and previous research}

Relocation rates of older adults are low. Older adults are usually satisfied with their home and residential situation and have no wish to move away from their familiar surroundings (Rogerson et al. 1997). Family networks play an important part in the residential satisfaction and well-being of older adults. Geographic proximity to family members increases the chance of family contact and support exchange. Considering the importance to family members of a small geographic distance, it could be expected that when older adults move, they will tend to make efforts to reduce this distance. Our first hypothesis, therefore, is: older adults relocate more often in the direction of children and siblings than away from them. Previous research on changes in distance between older parents and adult children has provided some evidence for this hypothesis, but the differences were not great (Law and Warnes 1982; Rogerson et al. 1997); Speare and McNally (1992) have found that among those elderly who did move, about $46 \%$ did not experience a significant change in proximity, but older adults for whom the distance to a child decreased outnumbered those for whom the distance increased by $37.4 \%$ to $16.4 \%$.

If the initial distance to the adult children is long, older adults have more to gain if they can move into the direction of their offspring than if this distance is shorter. Our second hypothesis, therefore, is that older adults are more inclined to relocate in the direction of family members as the initial distance to family members is great, and that they are less inclined to move away from them when the initial distance is small (see also Rogerson et al. 1993, 1997).

A short distance is particularly beneficial to frequent contact and to frequent support exchange, for example, help with the daily groceries, light housekeeping jobs, and personal 
care. Family members are very important in the contact and support networks of older adults (Miner and Uhlenberg 1997; De Jong Gierveld and Fokkema 1998). Reductions of distance could therefore be expected to occur particularly when the need or desire for support or contact is great. With increasing age and the accompanying greater chance of frailty, older adults' dependence on support increases. Health problems and impairments obviously also lead to a greater need for support. The need for support and contact with family members outside the household will also be greater when the older adult has no partner. At the same time, older adults are also important providers of support (Morgan et al. 1991; Van Tilburg et al. 1995; Lin and Rogerson 1995; Remery et al. 2000). Particularly around retirement age, when less or no time is spent in paid work but most older adults are still in good health, older adults have good opportunities to provide support to their family members. Those with grandchildren are frequently involved in childcare, and usually desire to spend time with their grandchildren and to participate in their lives. The third hypothesis, therefore, states: the chance of relocation nearer to family is greater, and the chance of relocation away from them smaller, when the older adult has a greater age, has health problems, lives alone, or has grandchildren. Longino and colleagues (1991) have found support for the hypothesis that the poorer the health, the greater is the chance of relocation. A deterioration in health has been found to increase the chance that older adults and their children move more closely together, but hardly any effect of age was found on the relocation of older adults in the direction of their children or away from them (Silverstein 1995; Rogerson et al. 1997). Widow(er)hood increases significantly the chance of a distance-reducing relocation (Rogerson et al. 1997), particularly when accompanied by a deterioration in health (Silverstein 1995). Conversely, single people living alone have a greater chance of a distance-increasing relocation (Rogerson et al. 1997).

Other demographic characteristics, such as gender and ethnicity, and also the characteristics of the children, seem to have hardly any significant relationship with a reduction of the geographic distance to children (Rogerson et al. 1997). The level of education and income can be seen as resources in knowledge and finance that older adults can draw on as an alternative to help from the family. Level of education and income could therefore be expected to lead to more distance-increasing and fewer distance-decreasing relocations. This expectation finds some support in the research of Rogerson et al. (1997). Their results show that, in the United States, education and income are positively related to the chance of increasing the distance between older adults and their children. However, at the same time, they find that a higher level of education also increases the chance of decreasing the distance between older adults and their children. Finally, there are some characteristics of the residential situation that might be relevant for decreasing or increasing the distance between older adults and their family. Remarkably, homeownership has been found to increase the chance of decreasing the distance between older adults and their children. The level of urbanisation does not appear to influence the chance of either increasing or decreasing distance (Rogerson et al. 1997), although De Boer (1999) has found a positive effect of living in a strongly urbanised area on the relocation chances of older adults. De Boer's finding could have been caused by the fact that, in the Netherlands, older city-dwellers frequently live in older apartments without elevators.

\section{Data and methods}

For the investigation of the influence of geographic distance to family on the relocation behaviour of older adults, data were drawn from the first wave of the main sample of the NKPS (Netherlands Kinship Panel Study, $N=8,155$; response rate of 45\%; see Dykstra 
et al. 2005, and www.nkps.nl). The NKPS data were gathered with the aim of charting the family in the Netherlands and facilitating research into family relationships and family solidarity. The NKPS is the first large Dutch database in which distances between the places of residence of family members are measured in detail by means of the postcodes of the home addresses. After weighting, the data are representative for the Dutch population from 18 through 79 years of age living in independent households. Older adults in institutional households (such as nursing homes) are not included in the sample.

The availability of the places of residence of family members is a great advantage of the NKPS. In this respect, the database is unique. Nevertheless, there are some limitations. Data about relocations are only available for the main respondent, not for family members. Also, background data for the family members are limited and known for only a small number of selected family members.

The 8,155 main respondents (anchors in NKPS terminology) are asked to supply the complete six-digit postcodes of the places of residence of various family members. There are some 400,000 of these postcodes in the Netherlands. A postcode usually covers no more than a part of a street and accommodates on average no more than 20 households. If the respondent does not know the postcode, it was reconstructed with the help of street and place. Linked to the postcodes are the coordinates of the RD Grid, the Dutch national system of coordinates that is used as the basis for geographical positioning. Should the respondent only know the place, then the coordinates of the municipality are used. The respondents are also asked to give the year in which they moved to the current address and the postcode of their previous place of residence, unless that was in the same place as the current one. Unfortunately, no relocation information is available for family members. Consequently, the place of residence of family members of the main respondent has to be assumed to have remained constant at the current location. That would not, of course, be correct in all cases; the chance that young people relocate is moreover greater than for older adults (Mulder 1993). This assumption is necessary to allow changes in distance following relocation to be analysed, but it produces an underestimate of the effects of distance to children and siblings. The distances are indeed only determined if one or more of these family members are still alive, do not live in the household, and the respondent is able and willing to respond to the question where these family members live. No distances are calculated if the family members live abroad.

The distance to family members is calculated in distance as the crow flies, not as journey time. Although journey time is more familiar to the respondent's everyday experience, the accuracy of subjective journey time measurements leaves much to be desired (Van Diepen 2000); Van der Vlist (2001) has shown that there is a very strong correlation between journey distance and journey time, namely 0.97 .

The two dependent variables indicate whether or not the respondent relocated-a maximum of 5 years ago - in combination with the direction of the relocation with respect to children and/or siblings. We define 'towards the family' and 'away from the family' as a reduction or an increase respectively in the distance to the nearest family member (child or sibling); in some analyses, we also involve the average distance to children and siblings. This approach has an important advantage over research into the change in distance to one specific family member. Proper account is taken of the fact that it is not laid down beforehand towards which child or which sibling a person relocates. If we would analyse dyads between particular family members, an increase in distance in the dyad under analysis could be accompanied by a decrease in distance to a different family member. A reduction of the smallest distance means that a person has in any case gone to live closer to one family member and in the new situation lives a shorter distance away from that family member 
than in the old situation. Our approach also has a disadvantage, however, in that it is only possible to involve the characteristics of the family members in the analyses to a very limited extent. The dependent variables each have three categories: not moving or moving only a short distance (within the same place of residence or else by less than $500 \mathrm{~m}$ ), relocated in the direction of children or siblings, and relocated away from children or siblings.

The independent variables are-in addition to journey distance-age, health, household composition, having or not having grandchildren and siblings, having or not having children, level of education, household income, home-ownership (owner occupation), and degree of urbanisation. For age, the upper limit had to be placed at 79 years. This led to some restrictions for our analysis, since research reveals that the need for help usually becomes critical from the 80th year (De Boer 1999). We set the lower level at 50 years. This range has the advantage that a distinction can be drawn between three 10-year age categories (50-59, 60-69, and 70-79), each with an adequate number of respondents. The total number of older adults in the sample amounted to 3,098. Of these, 2,441 people (79\%) have children living away from home; 2,672 people $(86 \%)$ have siblings living away from their home. Respondents are assigned the score 'health problems' if they have reported their health as 'poor' or 'very poor' or suffer from restrictions through a chronic sickness or handicap. The variables household composition (living alone or with a partner), the presence of grandchildren and siblings (for the purposes of the analysis of relocations with respect to children), and the presence of children living outside the household (for the purposes of the analysis of relocations with respect to siblings) are dichotomous. Some characteristics, such as the level of education, the household income, and the household composition were only measured at the moment of interview. Others could be reconstructed for the time before a potential relocation: the ownership of the dwelling and the level of urbanisation. The distance to children and siblings refers to the distance between the place of residence of the older adult before a potential relocation and the place of residence of children and siblings at the time of the interview. By 'before a potential relocation' we mean that the characteristic is assigned the value associated with the current dwelling if the respondent relocated to it more than 5 years previously, and the value associated with the previous dwelling if the respondent relocated 5 years or less ago.

The analysis consists of a descriptive part and a multivariate part. The descriptive part contains tables showing the distances of older adults to their children and to their siblings and tables indicating whether or not they relocate and the direction of the relocation. The multivariate part consists of multinomial logistic regression analyses. In the analysis of the influence of distance on relocation leading to a reduction or increase in distance, account must be taken of the occurrence of ceiling and floor effects. In the case of a very large distance, further increase would be unlikely or even impossible, while for a very small distance a further reduction would be unlikely or even impossible. To investigate the extent to which floor and ceiling effects occur, the analyses were repeated with the respondents with the $5 \%$ shortest and longest distances excluded.

Table 1 shows the characteristics of the sample with regard to the dependent and independent variables. Five cases lacked information on some independent variables and were left out in further analysis. Because older adults not always have children or siblings, the total number of cases in the multivariate analysis is different for the analyses of distance to children $(n=2,553)$ and distance to siblings $(n=2,852)$.

Even though our sample size is not small, the statistical power of the models is limited because the distribution of the values of the dependent variables is skewed: there are many non-movers and only a limited number of movers. We therefore report significance levels not only of 0.01 and 0.05 , but also 0.10 . 
Table 1 Descriptive statistics for the analysis of distance and relocation of family members of older adults

\begin{tabular}{|c|c|c|c|c|c|c|}
\hline & \multicolumn{3}{|c|}{ Regarding distance to children } & \multicolumn{3}{|c|}{ Regarding distance to siblings } \\
\hline & \multicolumn{2}{|c|}{ Frequencies } & \multirow[t]{2}{*}{ Mean } & \multicolumn{2}{|c|}{ Frequencies } & \multirow[t]{2}{*}{ Mean } \\
\hline & $N$ & Percentage & & $N$ & Percentage & \\
\hline \multicolumn{7}{|l|}{ Relocation with respect to children } \\
\hline Moved, distance increased & 151 & 5.9 & & & & \\
\hline Moved, distance decreased & 125 & 4.9 & & & & \\
\hline Not moved, or distance is equal & 2,277 & 89.2 & & & & \\
\hline \multicolumn{7}{|l|}{ Relocation with respect to siblings } \\
\hline Moved, distance increased & & & & 154 & 5.4 & \\
\hline Moved, distance decreased & & & & 160 & 5.6 & \\
\hline Not moved, or distance is equal & & & & 2,538 & 89.0 & \\
\hline Smallest distance to children $^{\mathrm{a}}$ & & & 15.51 & & & 15.01 \\
\hline Smallest distance to siblings ${ }^{\mathrm{a}}$ & & & 28.00 & & & 28.29 \\
\hline Age & & & 62.63 & & & 61.33 \\
\hline \multicolumn{7}{|l|}{ Children } \\
\hline Yes & 2,524 & 98.9 & & 2,427 & 85.1 & \\
\hline No & 29 & 1.1 & & 425 & 14.9 & \\
\hline \multicolumn{7}{|l|}{ Siblings } \\
\hline Yes & 2,439 & 95.5 & & 2,849 & 99.9 & \\
\hline No & 114 & 4.5 & & 3 & 0.1 & \\
\hline \multicolumn{7}{|l|}{ Grandchildren } \\
\hline Yes & 1,745 & 68.4 & & 1,534 & 53.8 & \\
\hline No & 808 & 31.7 & & 1,318 & 46.2 & \\
\hline \multicolumn{7}{|l|}{ Living alone } \\
\hline Yes & 748 & 29.3 & & 923 & 32.4 & \\
\hline No & 1,805 & 70.7 & & 1,929 & 67.6 & \\
\hline \multicolumn{7}{|l|}{ Health problems } \\
\hline Yes & 849 & 33.3 & & 935 & 32.8 & \\
\hline No & 1,704 & 66.8 & & 1,917 & 67.2 & \\
\hline \multicolumn{7}{|l|}{ Household income } \\
\hline$<€ 950$ & 908 & 35.6 & & 893 & 31.3 & \\
\hline$€ 950-<€ 1,350$ & 275 & 10.8 & & 327 & 11.5 & \\
\hline$€ 1,350-<€ 1,950$ & 343 & 13.4 & & 419 & 14.7 & \\
\hline$€ 1,950-<€ 2,950$ & 396 & 15.5 & & 467 & 16.4 & \\
\hline$>€ 2,950$ & 414 & 16.2 & & 505 & 17.7 & \\
\hline Unknown & 217 & 8.5 & & 241 & 8.5 & \\
\hline \multicolumn{7}{|l|}{ Level of education } \\
\hline Up to primary & 414 & 16.2 & & 421 & 14.8 & \\
\hline Lower secondary/lower vocational & 945 & 37.0 & & 1,001 & 35.1 & \\
\hline Higher secondary/middle vocational & 550 & 21.5 & & 609 & 21.4 & \\
\hline Higher vocational/university & 644 & 25.2 & & 821 & 28.8 & \\
\hline \multicolumn{7}{|l|}{ Homeowner $^{\mathrm{a}}$} \\
\hline Yes & 1,626 & 63.7 & & 1,833 & 64.3 & \\
\hline No & 927 & 36.3 & & 1,019 & 35.7 & \\
\hline \multicolumn{7}{|l|}{ Level of urbanisation ${ }^{\mathrm{a}}$} \\
\hline Not urbanised & 346 & 13.6 & & 377 & 13.2 & \\
\hline Hardly urbanised & 585 & 22.9 & & 627 & 22.0 & \\
\hline Moderately urbanised & 537 & 21.0 & & 568 & 19.9 & \\
\hline Strongly urbanised & 695 & 27.2 & & 782 & 27.4 & \\
\hline Very strongly urbanised & 390 & 15.3 & & 498 & 17.5 & \\
\hline Total & 2,553 & & & 2,852 & & \\
\hline
\end{tabular}

${ }^{a}$ Measured before potential relocation 


\section{Distance and relocations: descriptive results}

\subsection{Distance between older adults and their family}

How far away from or close to their family members do older adults in the Netherlands live? We first examined the differences between the smallest and the average distances of older adults to their children and of older adults to their siblings. The smallest distance is the distance between the older adult and the child living closest. For the average distance, first the average was calculated of the distances between the older adult and all children living away from home. If an older adult has just one child living away from home, the smallest distance is thus the same as the average distance. The averages were then calculated of the smallest and the average distances for various categories of older adults. We then had an 'average smallest distance' and an 'average average distance'. In the interests of readability, these were labelled simply 'smallest distance' and 'average distance'. The distances between older adults and their siblings were calculated in the same manner.

The average distance between older adults and their children was almost $30 \mathrm{~km}$ (Table 2; cf. also Mulder and Kalmijn 2006). At $16 \mathrm{~km}$, the smallest distance was considerably less than the average distance. The smallest distance to a child differs markedly and significantly according to age: for people in their 50s, the smallest distance was $20 \mathrm{~km}$; for those in their $60 \mathrm{~s}, 14 \mathrm{~km}$; and for those in their $70 \mathrm{~s}, 13 \mathrm{~km}$. It is striking that, while the shortest distance to a child is the shortest for the oldest category, the average distance to the children is conversely the longest for the oldest category. This result could indicate that children and/or parents take into account the proximity to the parents of at least one child in their choice of place of residence. The picture is somewhat more diffuse for the distance away from their siblings that older adults live. Those in their 70s live the furthest away from their siblings.

Whether measured by the average or the smallest distance, older adults live further away from their siblings than from their child(ren): 12 and $15 \mathrm{~km}$, respectively. This can probably be explained by the fact that most long-distance relocations take place before people have children. The distance between parents and children comes about primarily through the relocation of members of the younger generation, while the older generation usually stays in the same place. The distance between siblings comes about on the other hand by the relocation of several family members of the same generation.

\subsection{Relocations and changes in distance}

By drawing a distinction between older adults who have and have not relocated recently, we can investigate how the geographic distance to family members has changed by the

Table 2 Average and smallest distance in kilometres to children and siblings by age category

\begin{tabular}{lllll}
\hline Age category & $\begin{array}{l}\text { Smallest distance } \\
\text { to a child }\end{array}$ & $\begin{array}{l}\text { Average distance } \\
\text { to a child }\end{array}$ & $\begin{array}{l}\text { Smallest distance } \\
\text { to a sibling }\end{array}$ & $\begin{array}{l}\text { Average distance } \\
\text { to a sibling }\end{array}$ \\
\hline $50-59$ & 19.6 & 29.1 & 27.5 & 42.3 \\
$60-69$ & 13.9 & 26.6 & 25.7 & 42.2 \\
$70+$ & 13.4 & 31.9 & 34.1 & 48.3 \\
Total & 16.1 & 28.9 & 28.3 & 43.5 \\
$F$ & 10.96 & 3.93 & 8.10 & 4.47 \\
$p$ & 0.00 & 0.02 & 0.00 & 0.01 \\
\hline
\end{tabular}

Note: 'Average' should be read as 'average of average distances', 'smallest' as 'average of smallest distances' 
Table 3 Smallest and average distance to children from the previous and current dwelling (in kilometres) for recently relocated older adults by age category

\begin{tabular}{lcrrr}
\hline Age category & From previous dwelling & From current dwelling & $t$ & $p$ \\
\hline Smallest distance to child & & & \\
50-59 & 18.3 & 21.6 & -2.02 & 0.05 \\
$60-69$ & 16.7 & 18.4 & -0.72 & 0.47 \\
$70+$ & 15.2 & 12.4 & 0.82 & 0.07 \\
Total & 17.0 & 18.4 & -1.19 & 0.23 \\
Average distance to child & & & \\
50-59 & 29.0 & 32.3 & -2.03 & 0.04 \\
60-69 & 28.6 & 30.2 & -0.74 & 0.46 \\
70+ & 35.1 & 32.8 & 0.60 & 0.11 \\
Total & 30.3 & 31.7 & -0.33 & 0.18 \\
\hline
\end{tabular}

Note: 'Average' should be read as 'average of average distances', 'smallest' as 'average of smallest distances'

Table 4 Smallest and average distance to siblings from the previous and current dwelling (in kilometres) for recently relocated older adults by age category

\begin{tabular}{lcrrr}
\hline Age category & From previous dwelling & From current dwelling & $t$ & $p$ \\
\hline Smallest distance to sibling & & & \\
50-59 & 27.2 & 29.2 & -1.16 & 0.25 \\
$60-69$ & 30.1 & 30.4 & -0.10 & 0.92 \\
$70+$ & 34.0 & 31.1 & 1.59 & 0.12 \\
Total & 29.4 & 29.9 & -0.64 & 0.52 \\
Average distance to sibling & 43.6 & & & \\
50-59 & 45.7 & 47.0 & -1.99 & 0.05 \\
60-69 & 47.6 & 46.4 & -0.39 & 0.70 \\
70+ & 45.0 & 44.4 & 1.60 & 0.11 \\
Total & 46.3 & -1.08 & 0.28 \\
\hline
\end{tabular}

Note: 'Average' should be read as 'average of average distances', 'smallest' as 'average of smallest distances'

relocation. Of all older adults, $18 \%$ have relocated in the last 5 years to the current dwelling. The age categories hardly differ from each other. Of the people in their 50s, $19 \%$ have relocated in the last 5 years, as have $17 \%$ of those in their 60 s and 70 s. Table 3 shows the average of the smallest and average distance to children from the previous and current dwellings for relocated older adults in the three age categories. The comparable distances are shown for siblings in Table 4.

For the youngest category of older adults (50-59 years), both the smallest and the average distance to a child are significantly greater after a relocation than they were before. This finding also applies to the average distance to siblings. Conversely, for the oldest category (70-79 years), the smallest distance to children becomes smaller after relocation (significant at the 0.10 level). Evidence for our first hypothesis, that older adults relocate more in the direction of family members than away from them, is therefore weak for the oldest age category with respect to their child(ren) and not found for the younger older adults.

We then analysed the relocation behaviour of older adults with respect to the family in further detail. Table 5 shows, first, the proportion of older adults according to whether they relocated and the direction of the relocation. Second, Table 5 indicates the average smallest distance to children and to siblings from the previous and the current dwelling. We restricted ourselves to the shortest distance to a family member, since we consider that to 
Table 5 Relocation behaviour of older adults and average smallest distance in kilometres to family members from the previous and current dwelling according to relocation behaviour

\begin{tabular}{|c|c|c|c|c|c|c|}
\hline & No relocation & $\begin{array}{l}\text { Relocated- } \\
\text { smallest distance } \\
\text { remains equal }\end{array}$ & $\begin{array}{l}\text { Relocated- } \\
\text { smallest distance } \\
\text { has declined }\end{array}$ & $\begin{array}{l}\text { Relocated- } \\
\text { smallest distance } \\
\text { has increased }\end{array}$ & $F$ & $p$ \\
\hline $\begin{array}{l}\text { Relocations with } \\
\text { respect to children } \\
\text { (row percentage) }\end{array}$ & 82.6 & 7.3 & 4.6 & 5.5 & & \\
\hline \multicolumn{7}{|c|}{ Smallest distance to children from } \\
\hline Previous dwelling & 15.2 & 13.8 & 26.4 & 13.4 & 5.74 & 0.00 \\
\hline Current dwelling & 15.2 & 13.8 & 12.5 & 29.4 & 10.42 & 0.00 \\
\hline $\begin{array}{l}\text { Relocations with } \\
\text { respect to siblings } \\
\text { (row percentage) }\end{array}$ & 82.5 & 7.0 & 5.4 & 5.1 & & \\
\hline \multicolumn{7}{|c|}{ Smallest distance to siblings from } \\
\hline Previous dwelling & 27.7 & 21.4 & 31.3 & 28.1 & 7.51 & 0.00 \\
\hline Current dwelling & 27.8 & 21.4 & 27.7 & 44.0 & 9.55 & 0.00 \\
\hline
\end{tabular}

be more important for the opportunity for contact and mutual support than the average distance.

For four out of ten relocations of older adults, little or nothing changed in the smallest distance to a child; the difference in distance before and after relocation is less than half a kilometre. In contrast with the expectation, the share of relocations in the direction of children $(4.6 \%)$ was smaller than the share of relocations away from children (5.5\%). The picture is different for relocation with respect to the place of residence of siblings. Relocation in the direction of siblings is more frequent than away from them. The share of relocations of older adults by which the distance to their siblings became smaller was $5.4 \%$ compared with a share of $5.1 \%$ of the older adults for whom the distance to siblings after relocation became greater. It should be noted that the total percentages of relocations reported in Table 5 are a little smaller than the total relocation percentage measured for all older adults. These differences are brought about by the fact that the only older adults included in Table 5 are those who have children or siblings living away from their home. This does not concern all the older adults, but certainly the majority.

Table 5 also shows the differences in the smallest distances to children and to siblings before and after the relocation. Among the older adults who have not relocated, the distance to their child living closest is on average $15 \mathrm{~km}$. That figure hardly differs from that for the older adults for whom the distance to their child(ren) has not been changed by the relocation, namely $14 \mathrm{~km}$. The shifts in the distance between older adults and their child(ren) occur as a matter of course through what Silverstein (1995) refers to as divergence and convergence in the relocation of older adults. Older adults for whom the distance to their child living closest has become greater live after relocation considerably further away from that child, namely almost $30 \mathrm{~km}$ in comparison with $13 \mathrm{~km}$ previously. In contrast, with a distance-decreasing relocation, older adults have markedly reduced the distance to their child living closest, namely from 26 to almost $13 \mathrm{~km}$ on average. Since relocation with distanceincreasing occurs more often, and the difference in distance is greater than with distancedecreasing relocation, the total parent-child distance after relocation is greater than before relocation.

The changes in the smallest distances between older adults and siblings show a comparable pattern. The distances to siblings are indeed greater than to children, while distance-increasing 
and -decreasing relocation involves on average many fewer kilometres. Older adults who have not relocated live somewhat further away from their sibling living closest compared with older adults who, although they have relocated, have only moved by an inconsequential distance towards a sibling. For older adults who go to live further away from their siblings, the relocation increases the distance between them by on average $16 \mathrm{~km}$. For older adults who go to live closer, the distance becomes on average $3 \mathrm{~km}$ shorter. At first sight this might seem a small change, but from previous research it is known that even small differences in distance (for example, between 0-5 km and 5-20 km) are associated with great differences in care exchange (Knijn and Liefbroer 2006).

\section{Multivariate analyses}

In order to avoid making the multivariate analyses unnecessarily complicated, the category in which people do not relocate is combined with the category for relocation with no change in distance. The results of the multinomial logistic regression of increasing and reducing the smallest distance to children are shown in Table 6.

The distance to children before a potential relocation has a positive and strongly significant effect on the chance of a reduction in the distance to children. Thus, the further one lives from the child living closest, the greater the chance that one relocates in the direction of the child. This finding does not seem to have been brought about by the occurrence of a ceiling effect. In order to check to what extent a ceiling effect operates, another analysis was carried out which excluded the 5\% of older adults who lived the furthest from their child (for whom relocation all too readily leads to a distance reduction). This analysis produced no other effects. We checked in the same manner to see to what extent a floor effect occurs; here, the $5 \%$ of older adults who live closest to their child were excluded from the analysis. This analysis produced just as few different effects. The distance before the potential relocation has no significant effect on increasing the distance. Our hypothesis regarding the effect of distance is therefore supported for relocation in the direction of children, but not for relocation away from them.

Age appears to have a significant negative effect on both the increase and the reduction of the distance to children. These effects are of the same order of magnitude. The age effect seems to be brought about by a decrease in the propensity to move long distances with age rather than by an increasing tendency to go and live closer to the children. The absence in this analysis of any significant influence of health problems on relocation with a change in distance is surprising, in view of the results of other studies (De Boer 1999). Possibly here the age limit of the NKPS dataset has played a part, and this variable would have more effect if older adults above 80 years of age were taken up in the analysis. Finally, living alone has, completely in line with previous research (Litwak and Longino 1987), a strong positive effect on relocation with increase of distance. Evidently, quite different reasons for relocation operate for older adults living alone, such as the lack of obligations with respect to work or family. All in all, hardly any support was found for the existence of any influence from an older adult's need for care on relocation in the direction of children or away from them.

It was expected that having grandchildren would be likely to lead to more distancereducing relocations and fewer distance-increasing relocations of older adults. After controlling for the other independent variables, there does indeed seem to be a strong positive effect of the presence of grandchildren on the chance of the relocation of older adults in the direction of their children. According to the model, the odds for grandparents are $60 \%$ 
Table 6 Multinominal logit regression of the change in the smallest distance to children (reference: not moved or distance is equal)

\begin{tabular}{|c|c|c|c|c|c|}
\hline & \multicolumn{2}{|l|}{$\begin{array}{l}\text { Distance } \\
\text { decreased }\end{array}$} & \multicolumn{2}{|l|}{$\begin{array}{l}\text { Distance } \\
\text { increased }\end{array}$} & \multirow{2}{*}{$\begin{array}{l}\text { Distance } \\
\text { decreased } \\
\text { (ref: increased) }\end{array}$} \\
\hline & B & $\operatorname{Exp}(B)$ & $\mathrm{B}$ & $\operatorname{Exp}(B)$ & \\
\hline Constant & $-2.10 * *$ & & -0.89 & & \\
\hline Smallest distance to children ${ }^{\mathrm{a}}$ & $0.01 * * *$ & 1.01 & -0.00 & 1.00 & $* * *$ \\
\hline Age & $-0.03 * *$ & 0.97 & $-0.03 * *$ & 0.97 & \\
\hline Living alone (not alone $=0$ ) & 0.36 & 1.43 & $0.58 * * *$ & 1.78 & \\
\hline Health problems $($ none $=0$ ) & 0.25 & 1.28 & 0.06 & 1.06 & \\
\hline Grandchildren $($ none $=0)$ & $0.47 * *$ & 1.60 & -0.04 & 0.96 & $*$ \\
\hline Siblings $($ none $=0)$ & -0.08 & 0.93 & -0.11 & 0.90 & \\
\hline \multicolumn{6}{|l|}{ Level of education (up to primary $=0$ ) } \\
\hline Lower secondary/lower vocational & 0.36 & 1.43 & -0.27 & 0.76 & \\
\hline Higher secondary/middle vocational & 0.34 & 1.41 & 0.02 & 1.02 & \\
\hline Higher vocational/university & $0.73 * *$ & 2.07 & 0.22 & 1.24 & \\
\hline \multicolumn{6}{|l|}{ Household income $(<€ 950=0)$} \\
\hline$€ 950-<€ 1,350$ & 0.00 & 1.00 & -0.37 & 0.69 & \\
\hline$€ 1,350-<€ 1,950$ & 0.24 & 1.27 & 0.11 & 1.12 & \\
\hline$€ 1,950-<€ 2,950$ & 0.35 & 1.42 & -0.01 & 0.99 & \\
\hline$>€ 2,950$ & -0.04 & 0.96 & 0.32 & 1.37 & \\
\hline Unknown & 0.33 & 1.39 & -0.03 & 0.97 & \\
\hline Homeowner $^{\mathrm{a}}($ not owner $=0)$ & -0.30 & 0.74 & -0.16 & 0.85 & \\
\hline \multicolumn{6}{|l|}{ Level of urbanisation $^{\text {a }}$ (not urbanised $=0$ ) } \\
\hline Hardly urbanised & -0.17 & 0.84 & -0.34 & 0.71 & \\
\hline Moderately urbanised & -0.11 & 0.90 & -0.08 & 0.92 & \\
\hline Strongly urbanised & -0.13 & 0.88 & -0.10 & 0.90 & \\
\hline Very strongly urbanised & -0.21 & 0.81 & -0.02 & 0.98 & \\
\hline$-2 \log$ likelihood & 2,067 & & & & \\
\hline Improvement compared to null model $\left(\chi^{2}\right)$ & 62 & & & & \\
\hline$N$ & 2,553 & & & & \\
\hline$d f . p$ & $38,0.01$ & & & & \\
\hline
\end{tabular}

${ }^{a}$ Measured before potential relocation

$* p<0.10 ; * * p<0.05 ; * * * p<0.01$

greater than for older adults without grandchildren. The effect of being grandparent on the chance of relocation away from children is not significant. The chance of relocation either towards or away from children is not significantly influenced by having a sibling. Of these coefficients, only that for a high level of education and distance reduction is significant in the multivariate model, and then positively.

With the help of the same model, but on this occasion with another reference category (distance-increasing relocation), we investigated whether the effects of the independent variables on distance-decreasing and distance-increasing relocation also differ significantly from each other (see last column of Table 6). Two effects are significant. Distance has a strong significant positive effect on the chance of a decrease in the distance to children compared with an increase in distance; thus the greater the distance, the greater is the chance of a distance-reducing rather than a distance-increasing relocation. The presence of grandchildren also has a (marginally) significant positive effect: when there are grandchildren, the chance of a distance-reducing relocation is smaller than the chance of a distanceincreasing relocation. This finding is important, because it indicates that at least some of the decreases in distance are not coincidental. 
Table 7 Multinominal logit regression of the change in smallest distance to siblings (reference: not moved or distance is equal)

\begin{tabular}{|c|c|c|c|c|c|}
\hline & \multicolumn{2}{|c|}{$\begin{array}{l}\text { Distance } \\
\text { decreased }\end{array}$} & \multicolumn{2}{|l|}{$\begin{array}{l}\text { Distance } \\
\text { increased }\end{array}$} & \multirow{2}{*}{$\begin{array}{l}\text { Distance } \\
\text { decreased } \\
\text { (ref: increased) }\end{array}$} \\
\hline & $\mathrm{B}$ & $\operatorname{Exp}(B)$ & $\mathrm{B}$ & $\operatorname{Exp}(B)$ & \\
\hline Constant & $-1.81 * *$ & & $-1.42 *$ & & \\
\hline Smallest distance to siblings ${ }^{a}$ & $0.01 * * *$ & 1.01 & 0.00 & 1.00 & $* * *$ \\
\hline Age & $-0.03 * *$ & 0.97 & $-0.02 * *$ & 0.98 & \\
\hline Living alone (not alone $=0$ ) & $0.37^{*}$ & 1.44 & $0.33^{*}$ & 1.39 & \\
\hline Health problems $($ none $=0)$ & 0.29 & 1.33 & -0.04 & 0.96 & \\
\hline Children $($ none $=0)$ & 0.35 & 1.42 & 0.08 & 1.08 & \\
\hline \multicolumn{6}{|l|}{ Level of education (up to primary $=0$ ) } \\
\hline Lower secondary/lower vocational & -0.06 & 0.94 & -0.09 & 0.91 & \\
\hline Higher secondary/middle vocational & -0.02 & 0.98 & 0.29 & 1.33 & \\
\hline Higher vocational/university & 0.32 & 1.38 & 0.26 & 1.29 & \\
\hline \multicolumn{6}{|l|}{ Household income $(<€ 950=0)$} \\
\hline$€ 950-<€ 1,350$ & 0.03 & 1.03 & 0.02 & 1.02 & \\
\hline$€ 1,350-<€ 1,950$ & 0.26 & 1.30 & -0.27 & 0.76 & \\
\hline$€ 1,950-<€ 2,950$ & -0.17 & 0.85 & -0.20 & 0.82 & \\
\hline$>€ 2,950$ & 0.09 & 1.10 & 0.12 & 1.13 & \\
\hline Unknown & -0.28 & 0.75 & 0.01 & 1.01 & \\
\hline Homeowner ${ }^{\mathrm{a}}($ not owner $=0)$ & -0.27 & 0.76 & $-0.37 *$ & 0.69 & \\
\hline \multicolumn{6}{|l|}{ Level of urbanisation ${ }^{\mathrm{a}}$ (not urbanised $=0$ ) } \\
\hline Hardly urbanised & -0.27 & 0.76 & -0.12 & 0.89 & \\
\hline Moderately urbanised & 0.09 & 1.10 & 0.08 & 1.08 & \\
\hline Strongly urbanised & -0.04 & 0.96 & 0.07 & 1.07 & \\
\hline Very strongly urbanised & -0.21 & 0.81 & 0.10 & 1.11 & \\
\hline$-2 \log$ likelihood & 2348 & & & & \\
\hline Improvement compared to null model $\left(\mathrm{chi}^{2}\right)$ & 65 & & & & \\
\hline$N$ & 2,852 & & & & \\
\hline$d f . p$ & $36,0.00$ & & & & \\
\hline
\end{tabular}

${ }^{a}$ Measured before potential relocation

$* p<0.10 ; * * p<0.05 ; * * * p<0.01$

The results of the multinomial logistic regression of the increase and reduction of the smallest distance to siblings (Table 7) contain few significant effects. The coefficient of the smallest distance to siblings before the potential relocation is significant and positive for distance-reducing relocation. This effect is in agreement with our hypothesis that older adults are inclined to relocate closer to their family. Age has a significant negative effect on both distance-reducing and distance-increasing relocation among older adults. The negative effect on distance-reducing (with older age, the chance of a distance-decreasing relocation is smaller) is a little stronger than on distance-increasing (with older age, the chance of a distance-increasing relocation is smaller). This finding is in contrast with the hypothesis that the older-older adults have a greater chance of moving to live closer to their family than the younger-older adults have. Living alone has a significant positive effect that is comparable in scale on the chance of relocation by older adults both in the direction of siblings and away from them. Not having a partner therefore increases the chance of relocation in which the effect of a sibling's place of residence is less. Health problems or children living away from home have no significant effects. In short, we find no indications of an effect of need for care on relocation either in the direction of siblings or away from them. 
With respect to the difference between a reduction and an increase of distance to siblings, only distance produces an important significant effect. The distance to siblings before relocation has a significant positive effect on distance-reducing relocation.

\section{Conclusions}

Contact with family members and the mutual exchange of instrumental support are important for the wellbeing of older adults. With a small distance to family members, older adults have much to gain, so we supposed at the beginning of this study, since contacts and support are distance dependent. We expected that older adults would display strategic relocation behaviour by taking account of the distance to their family. With the new data from the Netherlands Kinship Panel Study (NKPS), it was possible for the first time to involve the distances to children and siblings in an empirical investigation of the relocation behaviour of older adults up to age 80 in the Netherlands. Moreover, the dataset provides the opportunity to include at the same time a number of relevant characteristics of older adults and their residential situation in the analysis.

An important finding is that the distance to family members before a potential relocation influences the chance that relocation takes place in the direction of those family members, both of children and siblings. The further away the older adults live, the greater is the chance that older adults come to live closer by. That ceiling or floor effects should occur is not very likely; the exclusion from the analysis of respondents with the shortest and longest distances, who easily determine the direction of the connection, did not lead to any different conclusions.

Second, we investigated whether distance-decreasing relocations of older adults with respect to the place of residence of their family members take place more often than distance-increasing relocations. With respect to siblings, the share of distance-decreasing relocations is indeed somewhat greater than the share of relocations that has an increase in distance as a consequence. This tendency is not found with respect to child(ren). Furthermore, the smallest distance after relocation with respect to both children and siblings is on average greater than it previously was. Only for the oldest older adults, those in their 70s, is the picture according to expectations; after relocation, they live somewhat closer to their child(ren) more often than they did before. With this distinction between older and younger older adults, this finding forms a further differentiation of the general picture that emerges from the literature (Law and Warnes 1982).

Including variables in the model that have something to do with older adults having contact with and giving help to their family has also turned out to be worthwhile. We conclude that the variable that forms an indication of older adults keeping in contact or giving help, namely being grandparents, influences in particular the chance that older adults move in the direction of their children, all else equal. On the other hand, the variable that indicates a need for care, namely having health problems, appears to have no significant effect. Furthermore, age itself appears to have a negative effect on decreasing distance. Thus, the provision of support by older adults and a desire for contact among the generations appears to contribute to the explanation of their relocation decisions rather than a need for help. Single-person households do indeed have a greater relocation mobility, but distances to family members do not appear to play a part in that. That the need for care plays hardly any part in relocation behaviour is not in line with findings from other research (Longino et al. 1991). The explanation for this difference can to some extent be sought in the age limit of the NKPS database; after all, health problems and mobility restrictions are particularly severe for those over 80. Moreover, the 
care sector in the Netherlands is extensive and accessible, so that many older adults feel able to be less dependent on the family for care. Furthermore, the Netherlands is a small and prosperous country. The distances to be bridged are not great, and automobility among both the young and the old has increased (Gagliardi et al. 2004). Consequently, within the Netherlands, geographic proximity may well be less necessary for the receiving and provision of instrumental support. Most of the older adults are also firmly attached to their homes. Even in a period of 5 years (this period is longer than that usually used in research into relocation behaviour), only about a fifth of the older adults had relocated.

A limitation of our analysis is that it is not known for which share of the older adults the distance to family members actually plays a part in considerations whether and where to relocate or how decisive that part is. Relocation takes place for motives of all kinds. These are not asked for in the NKPS data, let alone anything about motives not to relocate. In any event, for an unknown share of the relocations-possibly a majority-a change in the distance to children and siblings comes about in a purely chance manner. This reduces the probability of finding any significant effects.

Improvements in this analysis would be possible using the second wave of NKPS when it becomes available. This second wave will contain information about moves not only of older people, but also of their family members. Future studies might also turn to a longitudinal register of data including parent-child linkages, as is available now for some Nordic countries and, since very recently, also for the Netherlands (the Social-Statistical Database housed by Statistics Netherlands). Such data are less rich in background information about potential movers than NKPS, but the number of observations is greater by a factor of many hundreds.

In this article only the relocation behaviour of older adults has been examined. The converse of course is also possible, that children relocate in the direction of their parents. Research by Michielin and Mulder (2008) indeed suggests that the residential location of parents has a small but non-negligible impact on the relocation decisions of adult children.

Acknowledgements The Netherlands Kinship Panel Study is funded by grant 480-10-009 from the Major Investments Fund NWO and by the Netherlands Interdisciplinary Demographic Institute (NIDI), Utrecht University, the University of Amsterdam and Tilburg University. Clara Mulder's research for this paper was made possible by the Netherlands Organisation for Scientific Research (NWO), VICI grant no. 453-04-001. The paper is a thoroughly revised version of work that was done for the DGW/Nethur Partnership (reported in Van Diepen and Mulder 2005) and published in a Dutch journal (Van Diepen and Mulder 2006). The analyses were carried out on the zero-release of the data. Meanwhile, release 1 has become available. This new database contains a few corrections and a slightly different sample size in comparison with the zero release used. The changes are so minimal, we have not repeated the analyses.

Open Access This article is distributed under the terms of the Creative Commons Attribution Noncommercial License which permits any noncommercial use, distribution, and reproduction in any medium, provided the original author(s) and source are credited.

\section{References}

Bengtson, V. L. (2001). Beyond the nuclear family: The increasing importance of multigenerational bonds. Journal of Marriage and the Family, 63, 1-16.

Bengtson, V. L., \& Roberts, R. E. L. (1991). Intergenerational solidarity in aging families: An example of formal theory construction. Journal of Marriage and the Family, 53, 856-870.

Daatland, S. O., \& Lowenstein, A. (2005). Intergenerational solidarity and the family-welfare state balance. European Journal of Ageing, 2, 174-182.

De Boer, A. H. (1999). Housing and care for older people: A macro-micro perspective. Utrecht: Utrecht University. 
De Jong Gierveld, J., \& Fokkema, T. (1998). Geographical differences in support networks of older adults. Tijdschrift voor Economische en Sociale Geografie, 89, 328-336.

Dykstra, P. A., Kalmijn, M., Knijn, T. C. M., Komter, A. E., Liefbroer, A. C., \& Mulder, C. H. (2005). Codebook of the Netherlands Kinship Panel Study, a multi-actor, multi-method panel study on solidarity in family relationships, Wave 1. The Hague: Netherlands Interdisciplinary Demographic Institute (NKPS Working Paper No. 4).

Gagliardi, C., Leonardi, F., \& Marcellini, F. (2004). Basic national conditioning factors of mobility among elderly people. In H. Mollenkopf, F. Marcellini, I. Ruopplila, \& M. Tacken (Eds.), Ageing and outdoor mobility. Amsterdam: IOS Press.

Glaser, K., \& Tomassini, C. (2000). Proximity of older women to their children: A comparison of Britain and Italy. The Gereontologist, 40, 729-737.

Grundy, E., \& Shelton, N. (2001). Contact between adult children and their parents in Great Britain 1986-99. Environment and Planning A, 33, 685-697.

Hank, K. (2007). Proximity and contacts between older parents and their children: A European comparison. Journal of Marriage and Family, 69, 157-173.

Joseph, A. E., \& Hallman, B. C. (1998). Over the hill and far away: Distance as a barrier to the provision of assistance to elderly relatives. Social Science and Medicine, 46, 631-640.

Knijn, T. C. M., \& Liefbroer, A. C. (2006). More kin than kind: Instrumental support in families. In P. A. Dykstra, M. Kalmijn, T. C. M. Knijn, A. E. Komter, A. C. Liefbroer, \& C. H. Mulder (Eds.), Family solidarity in the Netherlands (pp. 89-105). Amsterdam: Dutch University Press.

Komter, A. E., \& Vollebergh, W. A. M. (2002). Solidarity in Dutch families: Family ties under strain? Journal of Family Issues, 23, 171-188.

Law, C. M., \& Warnes, A. M. (1982). The destination decision in retirement migration. In A. M. Warnes (Ed.), Geographical perspectives on the elderly. Chichester: John Wiley and Sons Ltd.

Lawton, L., Silverstein, M., \& Bengtson, V. (1994). Affection, social contact, and geographic distance between adult children and their parents. Journal of Marriage and the Family, 56, 57-68.

Lee, T. R., Mancini, J. A., \& Maxwell, J. W. (1990). Sibling relationships in adulthood: Contact patterns and motivations. Journal of Marriage and the Family, 52, 431-440.

Lin, G., \& Rogerson, P. A. (1995). Elderly parents and the geographic availability of their adult children. Research on Aging, 17, 303-331.

Litwak, E., \& Longino, C. F. (1987). Migration patterns among the elderly: A developmental perspective. The Gerontologist, 27, 266-272.

Longino, C. F., Jackson, D. J., Zimmerman, R. S., \& Bradsher, J. E. (1991). The second move: Health and geographic mobility. Journal of Gerontology, 1, 218-224.

Michielin, F., \& Mulder, C. H. (2008). Distance to parents and geographical mobility. Population Space and Place, 14, 327-345.

Miner, S., \& Uhlenberg, P. (1997). Intragenerational proximity and the social role of sibling neighbors after midlife. Family Relations, 46, 145-153.

Morgan, D. L., Schuster, T. L., \& Butler, E. W. (1991). Role reversals in the exchange of social support. Journal of Gerontology, 46, 278-287.

Mulder, C. H. (1993). Migration dynamics: A life course approach. Amsterdam: Thesis Publishers.

Mulder, C. H., \& Kalmijn, M. (2006). Geographical distances between family members. In P. A. Dykstra, M. Kalmijn, T. C. M. Knijn, A. E. Komter, A. C. Liefbroer, \& C. H. Mulder (Eds.), Family solidarity in the Netherlands. Amsterdam: Dutch University Press.

Remery, C., Van Doorne-Huiskes, A., Dykstra, P., \& Schippers, J. (2000). And what if grandma would also have a job? The future of informal childcare in The Netherlands [En als oma nu ook een baan heeft? De toekomst van de informele kinderopvang in Nederland]. Den Haag: NIDI.

Rogerson, P. A., Weng, R. H., \& Lin, G. (1993). The spatial separation of parents and their adult children. Annals of the Association of American Geographers, 83, 656-671.

Rogerson, P. A., Burr, J. A., \& Lin, G. (1997). Changes in geographic proximity between parents and their adult children. International Journal of Population Geography, 3, 121-136.

Rossi, A. S., \& Rossi, P. H. (1990). Of human bonding: Parent-child relations across the life course. New York: Aldine de Gruyter.

Silverstein, M. (1995). Stability and change in temporal distance between elderly and their children. Demography, 32, 29-45.

Smith, G. C. (1998). Residential separation and patterns of interaction between elderly parents and their adult children. Progress in Human Geography, 22, 368-384.

Speare, A., \& McNally, J. (1992). The relation of migration and household change among elderly persons. In A. Rogers (Ed.), Elderly migration and population redistribution: A comparative study. London: Belhaven Press. 
Tomassini, C., Wolf, D. A., \& Rosina, A. (2003). Parental housing assistance and parent-child proximity in Italy. Journal of Marriage and Family, 65, 700-715.

Van der Vlist, A. J. (2001). Residential mobility and commuting. Amsterdam: Tinbergen Institute, Research Series.

Van Diepen, A. (2000). Households and their spatial-energetic practices. Searching for sustainable urban forms. Utrecht/Groningen: Netherlands Geographical Studies, no. 266.

Van Diepen, A., \& Mulder, C. H. (2005). Afstand tot familieleden en woningmarktgedrag van ouderen. Utrecht: DGW/NETHUR Partnership, no. 31.

Van Diepen, A., \& Mulder, C. H. (2006). Afstand tot familieleden en verhuisgedrag van ouderen. Tijdschrift voor Sociologie, 27, 235-262.

Van Tilburg, T., Broese van Groenou, M., \& Thomése, F. (1995). Flow of support. In C. P. M. Knipscheer, J. De Jong Gierveld, T. G. Van Tilburg, \& P. A. Dykstra (Eds.), Living arrangements and social networks of older adults. Amsterdam: VU University Press. 